\title{
Knowledge, attitude and practice on breastfeeding in Klang, Malaysia
}

Tan KL

Department of Community Medicine, International Medical University, Bukit Jalil, 57000 Kuala Lumpur, Malaysia

\begin{abstract}
Introduction: In Klang, a district in the state of Selangor in Peninsular Malaysia, the effects of westernization and urbanization in recent years have had an impact on infant feeding. The objective of this study was to evaluate the practice, knowledge and attitude to breastfeeding and to assess factors associated with breastfeeding among women in Klang, Malaysia. Materials \& Methods: A cross-sectional study was carried out between June and October 2006 involving 220 women with infants aged six months from two randomly selected health clinics were selected and interviewed. Data on socio-demographic, infant factors, infant feeding in the first six months of life, knowledge and attitude towards breastfeeding were collected. Results: Exclusive breastfeeding was reported by $32.8 \%$, mixed feeding was reported by $14.5 \%$ and infant formula feeding was reported by $52.7 \%$ of the respondents. Chinese women were more likely not to practice exclusive breastfeeding compared to Malay women (odds ratio $18.27,95 \% \mathrm{Cl}: 3.95$, 84.54) while working women were more likely not to practice exclusive breastfeeding compared to non working women (odds ratio $3.75,95 \% \mathrm{Cl}: 1.64$, 8.55). Positive association with not exclusive breastfeeding included women with high household income and women with male infants. Malaysian women had a positive attitude but work place and short maternity leave had a negative impact on breastfeeding. Conclusion: Women of Chinese ethnicity, working, from high family income and with male infants were less likely to exclusively breastfeed. Adopting facilitatory measures at hospitals and work place could increase the rate of exclusive breastfeeding.
\end{abstract}

KEYWORDS: Exclusive breastfeeding, KAP, Malaysia

\section{INTRODUCTION}

Breastfeeding is the universally accepted means of infant feeding. The World Health Organization (WHO) recommends exclusive breastfeeding for the first six months of life, and thereafter continued breastfeeding until two years of age along with complementary foods. ${ }^{1}$ The benefits of breastfeeding for individuals and populations of mothers and children have been extensively documented. ${ }^{2,3,4}$

Over the past decade, the government of Malaysia has recognized the significance of breastfeeding and infant nutrition. According to Malaysia Third $\mathrm{Na}$ tional Health and Morbidity Survey (NHMS III) 2006, the prevalence of exclusive breastfeeding below six months was 14.5 (95\% Cl: $11.7,17.9) .5$ The effect of westernization and urbanization on breastfeeding in Malaysia is not well studied. To improve the rates of exclusive breastfeeding in Malaysia, specific information about the beliefs and practices that influence this outcome is needed.

Corresponding author;

Dr Tan Kok Leong

International Medical University

Department of Community Medicine

126, Jalan 19/155B Bukit Jalil

57000 Kuala Lumpur

Malaysia.

Email: kokleong_tan@imu.edu.my
This study was designed to evaluate the practice, knowledge and attitude towards breastfeeding and to assess factors associated with breastfeeding among women in Klang, Malaysia.

\section{MATERIALS AND METHODS}

\section{Study design}

A cross-sectional study was conducted in Klang, Malaysia involving 220 mothers with their six month old infants attending the Maternal and Child Health $(\mathrm{MCH})$ section of the government health clinics between 19th June and 19th October 2006. In Klang, there are eight government health clinics with their subsidiary community clinics providing health needs for the community. Two of the health clinics including their subsidiary community clinics were chosen for the study by random selection where one health clinic serves an urban population while the other serves a rural population.

\section{Sampling area}

The sampling method used was universal sampling. All eligible mothers who attended the clinics during the study period were included in the study. Data collection was carried out according to a schedule that was prepared. Data was collected from the two identified areas in the study at alternate weeks with designated days for each clinic. The specific days selected for data collection for each clinic coincided with the days 
where immunization was scheduled for the infants.

\section{Selection criteria}

The inclusion criteria in the study included all mother-infant pairs visiting the two selected health clinics including the subsidiary community clinics between 19th June and 19th October 2006. Mothers were excluded from the study if mothers were less than 18 years old, have a child with congenital malformation, infant with congenital malformation, infant taken care by caregivers during night time and infant not accompanied by mother at the clinic.

\section{Study instrument}

After consent from eligible mothers, a face to face interview using a pre-tested structured questionnaire was conducted by the author at the health clinics at respective days during the study period. The questionnaire was pre-tested among 35 eligible mothers from a different health clinic in the same district. The reliability of the questionnaire was conducted using the test-retest method with correlation coefficient of between 0.82 and 1.00. The questionnaire covered variables that included area of residence, mother's ethnicity, age, body mass index, marital status, education level, occupation, household income, parity, infant gender, birth weight and gestational weeks at birth. Breastfeeding was divided into three types: exclusive breastfeeding for a duration of six months (exclusive breastfeeding when an infant having received only breast milk from the mother, either directly from the breast or expressed; and no other liquids or solids with the exception of drops or syrups consisting of vitamins, mineral supplements, or medicines), mixed breastfeeding when infants received both infant formula and breastfeeding and infant formula when an infant received only artificial or infant formula after two weeks of life. All mothers were asked question regarding their main reasons for either breastfeeding or bottle feeding.

Questions with five-point Likert rating scale, from strongly disagree to strongly agree were used to assess women's knowledge and attitude towards breastfeeding. The original Likert scale was converted to $100 \%$ scale by multiplying the corresponding coefficient by 20. A higher score indicated a higher participants agreement with the item tested. Items testing knowledge included recommended breastfeeding duration, its benefit in decreasing the risk of acquiring diarrhea and its role in contraception. Questions that evaluated mother's attitude included mothers comfort with breastfeeding, cost, effect on care of other family members and effect on marital relationship. Items that tested community's attitude towards breastfeeding included feeling shy of breastfeeding in public places, role of community nurses and medical staff in encouraging breastfeeding, duration of maternity leave and facilitation of breastfeeding at work places.

\section{Statistical analysis}

All data in the questionnaire were coded and entered into Statistical Package for the Social Sciences (SPSS) version 11.0. Variables were described using frequency distribution for categorical variables and mean with standard deviation for continuous variables. The distribution of infant feeding by independent variables was tested using the chi-square test. Factors associated with no practicing exclusive breastfeeding were identified using univariate and multivariate logistic regression. Crude odds ratio and adjusted odds ratio and their 95\% confidence interval $(95 \% \mathrm{CI})$ were reported. A p-value of less than 0.05 was considered significant.

\section{RESULTS}

\section{Participant characteristics}

The mothers are ranged between 21 and 42 years with a mean age of $29.0 \pm 4.7$ years. The mean household income was 2,189.1 \pm 1136.7 Malaysian Ringgit (RM)/ month. About $60 \%$ of women were from urban area. Almost $55 \%$ of the women were of Malay ethnicity, most with less than diploma level education (87.3\%) and not working $(62.7 \%)$ (Table I).

\begin{tabular}{|c|c|c|}
\hline Variables & $\mathbf{n}$ & $\%$ \\
\hline \multicolumn{3}{|l|}{ Age (years) } \\
\hline$<30$ & 146 & 66.4 \\
\hline$\geq \mathbf{3 0}$ & 74 & 33.6 \\
\hline \multicolumn{3}{|l|}{ Area of Interview } \\
\hline Urban & 126 & 57.3 \\
\hline Rural & 94 & 42.7 \\
\hline \multicolumn{3}{|l|}{ Ethnicity } \\
\hline Malay & 120 & 54.5 \\
\hline Chinese & 60 & 27.3 \\
\hline Indian & 28 & 12.7 \\
\hline Others & 12 & 5.5 \\
\hline \multicolumn{3}{|l|}{ Education Level } \\
\hline Diploma or higher & 28 & 12.7 \\
\hline Less than diploma & 192 & 87.3 \\
\hline \multicolumn{3}{|l|}{ Occupation } \\
\hline Working & 82 & 37.3 \\
\hline Not Working & 138 & 62.7 \\
\hline \multicolumn{3}{|l|}{$\begin{array}{l}\text { Household Income } \\
\text { (RM / month) }\end{array}$} \\
\hline$<3,000$ & 170 & 77.3 \\
\hline$\geq 3,000$ & 50 & 22.7 \\
\hline \multicolumn{3}{|l|}{ Mode of Delivery } \\
\hline Vaginal & 198 & 90 \\
\hline $\begin{array}{l}\text { Instrumental / } \\
\text { Caesarian Section }\end{array}$ & 22 & 10 \\
\hline \multicolumn{3}{|l|}{ Parity } \\
\hline Primiparous & 68 & 30.9 \\
\hline Multiparous & 152 & 69.1 \\
\hline \multicolumn{3}{|l|}{ Infant Gender } \\
\hline Male & 106 & 48.2 \\
\hline Female & 114 & 51.8 \\
\hline
\end{tabular}


Table I. Socio-demographic characteristics of respondents $(n=220)$

Type of infant feeding by socio-demographic, maternal and infant characteristics of the 220 interviewed mothers, $32.8 \%$ were exclusive breastfeeders, $14.5 \%$ were mixed breastfeeders and $52.7 \%$ practice infant formula feeding. Table II shows the type of feeding by socio-demographic, maternal and infant characteristics.

\begin{tabular}{|c|c|c|}
\hline Variables & $\mathbf{n}$ & \% \\
\hline \multicolumn{3}{|l|}{ Age (years) } \\
\hline$<30$ & 146 & 66.4 \\
\hline$\geq 30$ & 74 & 33.6 \\
\hline \multicolumn{3}{|l|}{ Area of Interview } \\
\hline Urban & 126 & 57.3 \\
\hline Rural & 94 & 42.7 \\
\hline \multicolumn{3}{|l|}{ Ethnicity } \\
\hline Malay & 120 & 54.5 \\
\hline Chinese & 60 & 27.3 \\
\hline Indian & 28 & 12.7 \\
\hline Others & 12 & 5.5 \\
\hline \multicolumn{3}{|l|}{ Education Level } \\
\hline Diploma or higher & 28 & 12.7 \\
\hline Less than diploma & 192 & 87.3 \\
\hline \multicolumn{3}{|l|}{ Occupation } \\
\hline Working & 82 & 37.3 \\
\hline Not Working & 138 & 62.7 \\
\hline \multicolumn{3}{|l|}{$\begin{array}{l}\text { Household Income } \\
\text { (RM / month) }\end{array}$} \\
\hline$<3,000$ & 170 & 77.3 \\
\hline$\geq 3,000$ & 50 & 22.7 \\
\hline \multicolumn{3}{|l|}{ Mode of Delivery } \\
\hline Vaginal & 198 & 90 \\
\hline $\begin{array}{l}\text { Instrumental / } \\
\text { Caesarian Section }\end{array}$ & 22 & 10 \\
\hline \multicolumn{3}{|l|}{ Parity } \\
\hline Primiparous & 68 & 30.9 \\
\hline Multiparous & 152 & 69.1 \\
\hline \multicolumn{3}{|l|}{ Infant Gender } \\
\hline Male & 106 & 48.2 \\
\hline Female & 114 & 51.8 \\
\hline
\end{tabular}

Table II. Type of feeding by socio-demographic, maternal and infant characteristics

* Row Percentage

** Statistically significant at $p<0.05$

Type of feeding was independent of area of residence, mode of delivery, parity, infant birth weight and infant gestational age. In this study, chinese mothers were least likely to breastfeed their infants. Women with higher level of education and higher household income were less likely to breastfeed. Similarly, employed mothers and mothers with a BMI of $<25 \mathrm{~m} / \mathrm{kg} 2$ were less likely to breastfeed.

Twenty nine percent of all women in this study reported that mothers' employment being the main reason for infant formula feeding and another $48 \%$ thought that having insufficient breast milk was the reason for failed breastfeeding. Seventy one percent of all women reported that 'Breast milk is the best for the infant' as the main reason for practicing breastfeeding.Multivariate analysis of factors associated with not exclusively breastfeed

Factors associated with not full breastfeeding were entered into a logistic regression model. Chinese women were more likely not to practice exclusive breastfeeding compared to Malay women (odds ratio 18.27, 95\% $\mathrm{Cl}: 3.95$, 84.54). Working women were more likely not to practice exclusive breastfeeding compared to non working women (odds ratio $3.75,95 \% \mathrm{Cl}: 1.64,8.55$ ). Women with household income $\geq \mathrm{RM} 3,000$ were 3.68 times more likely not practice exclusive breastfeeding $(95 \% \mathrm{Cl}: 1.52,12.72)$ compared to women with household income $<$ RM3,000 while women with male infants were 1.98 times more likely not practice exclusive breastfeeding ( $95 \% \mathrm{Cl}: 1.08,3.87)$ compared to women with female infants (Table III).

\begin{tabular}{|c|c|c|}
\hline Variables & $\begin{array}{c}\text { Unadjusted OR } \\
\text { (95\% CI) }\end{array}$ & $\begin{array}{l}\text { Adjusted OR } \\
\text { (95\% Cl) }\end{array}$ \\
\hline \multicolumn{3}{|l|}{ Age (years) } \\
\hline$<30$ & 1 & 1 \\
\hline \multicolumn{3}{|l|}{ Ethnicity } \\
\hline Malay & 1 & 1 \\
\hline Chinese & $14.00(4.77,41.03)$ & $\begin{array}{c}18.27(3.95 \\
84.54)=\end{array}$ \\
\hline Indian & $3.67(1.39,9.68)$ & $2.59(0.89,7.51)$ \\
\hline Others & $5.00(1.05,23.79)$ & $6.82(1.36,34.07)$ \\
\hline \multicolumn{3}{|l|}{$\begin{array}{l}\text { Education } \\
\text { Level }\end{array}$} \\
\hline $\begin{array}{l}\text { Diploma or } \\
\text { higher }\end{array}$ & $3.29(1.10,9.87)$ & $3.09(0.39,24.52)$ \\
\hline $\begin{array}{l}\text { Less than } \\
\text { diploma }\end{array}$ & 1 & 1 \\
\hline \multicolumn{3}{|l|}{ Occupation } \\
\hline Working & $3.52(1.81,6.86)$ & $3.75(1.64,8.55)^{2}$ \\
\hline Not Working & 1 & 1 \\
\hline \multicolumn{3}{|l|}{$\operatorname{BMI}\left(\mathrm{m} / \mathrm{kg}^{2}\right)$} \\
\hline$<25.0$ & 1 & 1 \\
\hline \multicolumn{3}{|l|}{$\begin{array}{l}\text { Household } \\
\text { Income (RM } \\
\text { /month) }\end{array}$} \\
\hline$<3,000$ & 1 & 1 \\
\hline$\geq 3,000$ & $4.65(1.88,11.50)$ & $3.68(1.52,12.72)$ \\
\hline \multicolumn{3}{|c|}{ Infant Gender } \\
\hline Male & $2.08(1.17,3.72)$ & $1.98(1.08,3.87)$ \\
\hline Female & 1 & 1 \\
\hline
\end{tabular}

Table III. Factors associated with not exclusively breastfeed using logistic regression

* Statistically significant at $p<0.05$ 
Knowledge and attitude to breastfeeding

Regarding women's knowledge, on a scale of 100 , 'breastfeeding for three months is considered long enough' scored 78, indicating agreement with this item. Most women agreed with the statement that breastfeeding is a good contraceptive method (score = 68 ) and that breastfeeding decreased diarrhea (score = 89) (Table IV).
Regarding the community's attitude to breastfeeding, on a scale of 100, the average score for answers are shown in Table IV. Mothers were not satisfied with the length of the maternity leave and the workplace facilities for breastfeeding. Malaysian women's positive attitude was reflected in their thinking that breastfeeding was easier than feeding infant formula and it was less expensive than feeding infant formula.

$\begin{array}{lr}\text { Item } & \begin{array}{c}\text { Avera } \\ \text { Score }\end{array} \\ \text { Knowledge } & 78 \\ \text { Three months of breastfeeding is long enough. } & 68 \\ \text { Breastfeeding is a good contraceptive method. } & 89 \\ \text { Breastfeeding decreases diarrhoea. } & 87 \\ \text { Attitude } & 61 \\ \text { Breastfeeding is easier than feeding infant formula. } & 66 \\ \text { It is not difficult for breastfeeding mother to care for the family- } & 83 \\ \text { Breastfeeding has no negative effect on marital relationship. } & 50 \\ \text { Breastfeeding is a good way to decrease family expenses. } & 22 \\ \text { Feeding infant formula keeps the body well shaped and prevents over-weight. } & 76 \\ \text { Community encourages breastfeeding over feeding infant formula. } & 34 \\ \text { Doctors and nurses encourage breastfeeding- } & 26 \\ \text { Maternity leave of two months is enough to successfully breastfeed. } & \\ \text { Work places provide designated areas for breastfeeding- } & \end{array}$

Table IV. Mothers' knowledge and attitudes towards infant feeding

* On 100 point scale, a higher score indicated a higher participant's agreement with the item tested.

\section{DISCUSSION}

This cross-sectional study showed that $32.8 \%$ of the respondents exclusively breastfeed for six months while $14.5 \%$ practice mixed infant feeding. These rates were higher that those reported in Malaysia Third National Health and Morbidity Survey 20065 and in the USA for the same ages 6 but less than those reported in Eastern countries. ${ }^{7,8}$ This may reflect a difference in the socio-demographic and cultural status. In Malaysia, less-educated women were more likely to breastfeed than women with higher education levels. In contrast, education had a positive effect on breastfeeding in Western communities and developed countries.9,10

This study showed that factors associated with not practicing exclusive breastfeeding were mothers' ethnicity, working status, household income and infant gender. In Malaysia, health services are provided by both government and private hospitals. Among the 116 government hospitals, 114 were designated as baby friendly hospitals while only six private hospitals were awarded with the status. ${ }^{11}$ Hospitals and work places without facilities for breastfeeding can be detrimental for breastfeeding. Cohen et al showed that women employed by businesses that are 'breastfeeding friendly' were able to maintain a breastfeeding regimen for at least six months at rates comparable to the rate of women who are not employed outside home. ${ }^{12}$ Ong et al showed that inadequate facility for breastfeeding at work place significantly reduces the duration of breastfeeding among working mothers. ${ }^{13}$

In Malaysia, women employed in the government sector were given two months maternity leave while for private sector the leave could range from two weeks to two months. Government policies regarding longer maternity leave both for government and private sectors should be considered. The respondent in this study were not satisfied with the length of their maternity leave and they did not think that workplaces provided the right environment for successful breastfeeding.

Seventy one percent of all women reported that 'Breast milk is the best for the infant'. Baby friendly hospital initiative and promotion of breastfeeding in health clinics that emphasize the advantages of breast milk over infant formula milk were probably the reason in maintaining this practice. The major reason identified in this study for infant formula milk was mothers' concern of insufficient breast milk (48\%). Studies throughout the world have identified that concern about milk supply was the most common reason women stop breastfeeding. ${ }^{14,15,16}$ Education for women regarding time needed for colostrum to change to transitional milk and educating regarding ways of successful breastfeeding can be valuable in 
decreasing concern about milk supply. Mothers need to be educated on the importance of feeding on demand to ensure adequate supply of breast milk.

Malaysian women reported that health care workers encourage breastfeeding but not the community. In Malaysia, breastfeeding in public places is viewed as a taboo due to the actual or gesture of exposing the breast. Education and awareness must be imparted to the community regarding breastfeeding to eliminate the hostility among the community on women who needed to breastfeeding in public places.

A limitation of this study was its cross-sectional design. In order to minimize recall bias, the age of infant included in the study was six months. Another limitation was that the respondents were selected from the government health clinics only. Further study is needed to include respondents from the private sector.

\section{CONCLUSION}

This study showed that only one-third of the respondents exclusively breastfeeding for six months. Women of Chinese ethnicity, working, from high family income and with male infants were less likely to exclusively breastfeed. It is speculated that having Baby Friendly hospitals and work places would probably be steps in the right direction to increase the rate of six months exclusive breastfeeding.

\section{ACKNOWLEDGEMENT}

The author gratefully acknowledges the willing assistance and cooperation given by all the mothers in the study, the District Officer of Health, Klang District and all the nurses. This study would not have been possible without their assistance.

\section{REFERENCES}

1. WHO. The optimal duration of exclusive breastfeeding: Report of an expert consultation. Geneva: World Health Organization, 2001.

2. Brown KH, Black RE, de Romana GL, de Kanashiro HC. Infant-feeding practices and their relationship with diarrhoeal and other diseases in Hauscar (Lima) Peru. Pediatrics 1989; 83:31 - 40

3. Popkin BM, Adair L, Akin JS, Black R, Briscoe MS, Flieger W. Breastfeeding and diarrhoeal morbidity. Pediatrics 1990; 86:874 - 82

4. WHA. Infant and young child nutrition. Geneva: World Health Assembly, 2001.

5. NIH. The Third National Health and Morbidity Survey 2006 (NHMS-III) Report. Malaysia: National Institute of Health, Ministry of Health, 2008.

6. USDHS. Healthy people 2020. Conference Ed. Washington (DC): US Department of Health and Human Services (USDHS), 2000: 47-8.
7. Hajian-Tilaki. Factors associated with the pattern of breastfeeding in the north of Iran. Ann Hum Biol 2005; 32:702-13

8. Khassawneh M, Khader $\mathrm{Y}$, Amarin Z, Alkafajei A. Knowledge, attitude and practice of breastfeeding in the north of Jordan: a cross-sectional study. Int Breast feeding J 2006; 1:17

9. Di Napoli A, Di Lallo D, Pezzotti P, Forastiere F, Porta D. Effects of parental smoking and level of education on initiation and duration of breastfeeding. Acta Paediatr 2006; 95:678 85

10. Forster DA, McLachlan HL, Lumley J.

Factors associated with breastfeeding at six months postpartum in a group of Australian women. Int Breastfeeding J 2006; 1:18

11. MOH. Annual Report 2006. Malaysia: Division of Family Health Development, Ministry of Health, 2007.

12. Cohen R, Mrtek MB. The impact of two corporate lactation programs on the incidence and duration of breastfeeding by employed mothers. Am J Health Promot 1994; 8:436-41

13. Ong G, Yap M, Foo LL, Tai BC. Impact of working status on breastfeeding in Singapore. Eur J Public Health 2005; 15:42430

14. Binns CW, Scott JA. Breastfeeding: reasons for starting, reasons for stopping and problems along the way. Breastfeed Rev 2004; 10:13-9

15. Heath AL, Tuttle CR, Simons MS, Cleghorn CL, Parnell WR. A longitudinal study of breast feeding and weaning practices during the first year of life in Dunedin, New Zealand. J Am Diet Assoc 2002; 102:937-43

16. Kong SKF, Lee DTF. Factors influencing decision to breastfeed. J Adv Nursing 2004; 4 6:369-79 
THE INTERNATIONAL MEDICAL JOURNAL

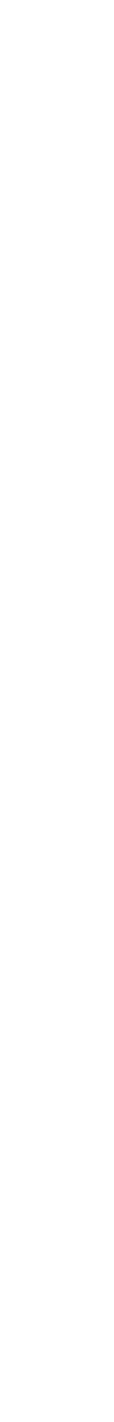

